

\section{Sumário}

I. INTRODUÇÃO

The Datasphere and the Law: New Space, New Territories ...................................III Jean-Sylvestre Bergé e Stéphane Grumbach

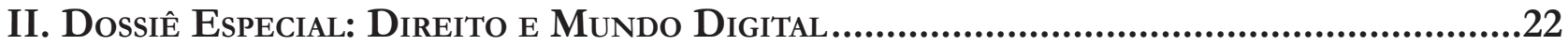

A. Criptomoedas e tecnologia blockchain ......................................................................23

Passado, presente e futuro da CRiptografia forte: DesenVolvimento tecnológico e

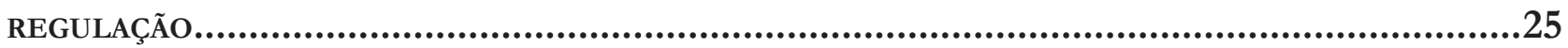
Jacqueline de Souza Abreu

Tratamento JuRídico Das CRIPTOMOEDAS: A DiNÂMiCA DOS BitCOINS E O CRIME DE LAVAGEM

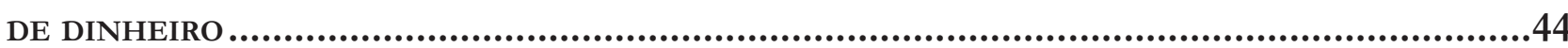
Mariana Dionísio de Andrade

TERRITÓRIO DAS CRIPTOMOEDAS: LIMITES À REGULAMENTAÇÃo ESTATAL QUANTO À CIRCULAÇÃO DE MOEDAS NO CIBERESPAÇO E POSSÍvEIS ALTERNATIVAS ..................................................61 Ranidson Gleyck Amâncio Souza

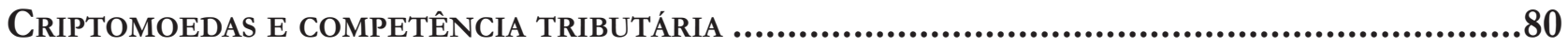
Guilherme Broto Follador

BitCoIn E A (IM)POSSIBILIDAde DE SUA PROIBIÇÃO: UMA VIOLAÇÃo À SOBERANIA Do EsTAdo?106 Rodrigo Valente Giublin Teixeira e Felipe Rangel da Silva

BlockChain e Agenda 2030

Danielle Mendes Thame Denny, Roberto Ferreira Paulo e Douglas de Castro

A reconstruÇão da JURISDição PELO ESPAÇO Digital: REDES SOCIAIS, BLOCKCHAIN E CRIPTOMOEDAS COMO PROPULSORES DA MUDANÇA.

Maria Edelvacy Pinto Marinho e Gustavo Ferreira Ribeiro

B. Proteção de dados e provedores de Internet

O tempo e O espaço. Fragmentos do marco Civil da internet: paradigmas de Proteção DA DIGNIDADE HUMANA 160 Maria Celeste Cordeiro Leite dos Santos e Marilene Araujo 
O PRojeto de Lei de PRoteção de dAdos PEssoais (PL 5276/2016) NO MUNDO do Big DATA: O FENÔMENO DA DATAVEILLANCE EM RELAÇÃo À UTILIZAÇÃO DE METADADOS E SEU IMPACTO NOS DIREITOS HUMANOS ................................................................................... 185

Elias Jacob de Menezes Neto, Jose Luis Bolzan de Morais e Tiago José de Souza Lima Bezerra

DignidADE HUMANA NA WEBESFERA GOVERNAMENTAL BRASILEIRA...................................200 Luciana Cristina Souza

CiberespaÇo E CONTEÚdo OFENSIVO GERAdo POR TERCEIROS: A PROTEÇão DOS DiREITOS DE PERSONALIDADE E A RESPONSABILIZAÇÃo CIVIL DOS PROVEDORES DE APLICAÇÃO, À LUZ DA JURisprudênCIA do Superior Tribunal de JustiçA................................................ 217 Cristiano Colombo e Eugênio Facchini Neto

A responsabilidade CIVIL pelos atos autônomos da INTEligÊnCIA ARTIFICIAL: NOTAS iniciais sobre a resolução do Parlamento Europeu ...........................................239 Thatiane Cristina Fontão Pires

Rafael Peteffi da Silva

SHARENTING, LIBERDADE DE EXPRESSÃO E PRIVACIDADE DE CRIANÇAS NO AMBIENTE DIGITAL: O PAPEL DOS PROVEDORES DE APLICAÇÃo NO CENÁRIO JURÍDICO BRASILEIRO. 256 Fernando Büscher von Teschenhausen Eberlin

THE DICHOTOMY BETWEEN SMART METERING AND THE PROTECTION OF CONSUMER'S PERSONAL DATA IN BRAZILIAN LAW..

Lucas Noura Guimarães

O CYBERBULlying E OS LIMITES DA LIBERDADE DE EXPRESSÃO 295 Janile Lima Viana, Cinthia Meneses Maia e Paulo Germano Barrozo de Albuquerque

O Supremo Tribunal Federal e o discurso de ódio nas redes sociais: exercício de DIREITO VERSUS LIMITES À LIBERDADE DE EXPRESSÃO

Carlo José Napolitano e Tatiana Stroppa

ANÁlise COMPARAdA DE ESTRATÉgIAS DE ENFRENTAMENTO A “REVENGE PORN” PELO MUNDO .... 334 Natália Neris, Juliana Pacetta Ruiz e Mariana Giorgetti Valente

USO INDEVIDO DE REDES SOCIAIS E APLICATIVOS DE MENSAGENS INSTANTÂNEAS NO AMBIENTE LABORAL 
ENSAIO SOBRE A PROMESSA JURÍDICA DO ESQUECIMENTO: UMA ANÁLISE A PARTIR DA PERSPECTIVA DO PODER SIMBÓliCo DE BOURDIEU 368 Joana Machado e Sergio Negri

UMA AGENDA PARA O DIREITO AO ESQUECIMENTO NO BRASIL. 384 Bruno de Lima Acioli e Marcos Augusto de Albuquerque Ehrhardt Júnior

NÃo AdIANTA NEM TENTAR ESQUECER: UM ESTUdo SOBRE O DIREITO AO ESQUECIMENTO...... 412 José Augusto Fontoura Costa e Geraldo Miniuci

A aplicaÇão do direito ao ESQUecimento aos agentes delitivos: uma ANÁlise aCERCA da PONDERAÇÃO ENTRE O DIREITO À IMAGEM E AS LIBERDADES DE EXPRESSÃO E DE INFORMAÇÃO437 Paulo Afonso Cavichioli Carmona e Flávia Nunes de Carvalho Cavichioli Carmona

DiREITO AO ESQUECIMENTO: NA SOCIEDADE INFORMACIONAL HÁ ESPAÇO PARA O EPÍLOGO DA MÁQUINA DE TORTURA KAFKIANA?

Alexandre Antonio Bruno da Silva e Marlea Nobre da Costa Maciel

ESQUECIMENTO, INTERNET E “PREFERÊNCIA” DA INFORMAÇÃO: POSSIBILIDADES DE APLICAÇÃO DA DOUTRINA DOS PREFERRED RIGHTS DA JURISPRUDÊNCIA NORTE-AMERICANA AO CASO BRASILEIRO 484

Maria Vital da Rocha, Isaac Rodrigues Cunha e Karin de Fátima Rodrigues Oliveira

D. Propriedade intelectual 510

Direitos AUtorais E MÚSICA: TECNOLOGIA, DiREITO E REGUlaÇão Marcia Carla Pereira Ribeiro, Cinthia Obladen de Almendra Freitas e Rubia Carneiro Neves

Direito AUTORAL NA CIBERCUlTURA: UMA ANÁLISE Do ACESSO AOS BENS IMATERIAIS A PARTIR DAS LICENÇAS CREATIVE COMMONS 4.0.

Gabriela Maia Rebouças e Fernanda Oliveira Santos

E. Políticas públicas e novas tecnologias.

SALTO DIGITAL NAS POLÍTICAS PÚBLICAS: OPORTUNIDADES E DESAFIOS .561 Marcelo D. Varella, Clarice G. Oliveira e Frederico Moesch

Fostering E-gOVERnMENT IN BRAZIL: A CASE STUdY OF DIGITAL CERTIFICATION ADOPTION.585 Lamartine Vieira Braga

DEMOCRATIZAÇÃo NA ERA Digital: DESAFIOS PARA UM DiÁlOgo CONSCIENTE E IGUALITÁRIO.602 Raquel Cavalcanti Ramos Machado e Laura Nathalie Hernandez Rivera 
REDES SOCIAIS E CROWDSOURCING CONSTITUCIONAL: A INFLUÊNCIA DA CIBERDEMOCRACIA SOBRE A GÊNESE E A INTERPRETAÇÃO DE NORMAS CONSTITUCIONAIS ...................................... 618 Igor Ajouz

MARCo CIVIL DA INTERNET E POLÍTICA PÚbliCA DE TRANSPARÊNCIA: UMA ANÁLISE DA E-DEMOCRACIA E DO COMPLIANCE PÚBLICO.

Juliana Costa Zaganelli e Wallace Vieira de Miranda

Políticas públicas bRasileiras de COMPUTAÇÃo EM NUVEM: ANÁLISE DOCUMENTAL dos RELATÓRIOS DO GLOBAL CLOUD COMPUTING SCORECARD

Lucas dos Santos Costa e Marcos Fernando Machado de Medeiros

O uso monopolista do Big Data POR EMpresas de aplicativos: políticas públicas para UM DESENVOLVIMENTO SUSTENTÁVEL EM CIDADES INTELIGENTES EM UM CENÁRIO DE ECONOMIA CRIATIVA E DE LIVRE CONCORRÊNCIA...................................................................6 672 José Antonio Remedio e Marcelo Rodrigues da Silva

1. Introdução

2. A urbanização das cidades e a sociedade em rede: economia criativa, colaborativa e compartilhada como formas de concretização de funções sociais da cidade.

4. Concorrência e Big Data Business relevantes às Smart Cities: estudo de caso envolvendo a aquisição do Waze pelo Google

5. Considerações finais

Referências

III. OUTROS TEMAS

COMO SALVAR O SISTEMA DE REPERCUSSÃo GERAL: TRANSPARÊNCIA, EFICIÊNCIA E REALISMO NA escolha do Que o Supremo Tribunal Federal vai Julgar.. .696 Luís Roberto Barroso e Frederico Montedonio Rego

Precariedade do sistema penitenciário brasileiro como base temática para a proibição OU LEGALIZAÇÃO DAS DROGAS. 715

Lilian Rose Lemos Rocha e José Eduardo Cardozo

A terceira margem do constitucionalismo republicano: uma Crítica A Frank Michelman. .732

Daniel Barcelos Vargas

Medida PRovisória E CONTROLE DE CONSTITUCIONALIDADE: RELEVÂNCIA, URGÊNCIA E PERTINÊNCIA TEMÁTICA

Clarice G. Oliveira e José Levi Mello do Amaral Júnior 
ОвJETO E CONCEITO DO DIREITO ADMINISTRATIVO: REVISÃo CRÍTICA...................................765 Carlos Bastide Horbach

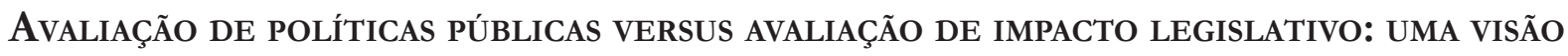
DICOTÔMICA DE UM FENÔMENO SINGULAR

Aparecida de Moura Andrade e Héctor Valverde Santana

LOS AVATARES DEL INTERÉS DEFINIDO EN TÉRMINOS DE PODER EN LA FORMULACIÓN DE LAS POLÍTICAS PÚBLICAS

Louis Valentin Mballa

CONSEQUENCIALISMO JUdicial NA MODUlaÇão DE EFEITOS DAS DECISÕES DECLARATÓRIAS DE INCONSTITUCIONALIDADE NOS JULGAMENTOS DE DIREITO TRIBUTÁRIO 819

Fernando Leal e Daniela Gueiros Dias

JudicializaÇão da SAÚde: A dignidade da PESSOA HuMana E A ATUAÇão do Supremo Tribunal Federal no caso dos medicamentos de alto custo

Fabricio Veiga Costa, Ivan Dias da Motta e Dalvaney Aparecida de Araújo 


\title{
Uso indevido de redes sociais e aplicativos de mensagens instantâneas no ambiente laboral*
}

\section{Wrong use of social networks and snapshots messages at workplace}

\author{
Eloy Pereira Lemos Junior** \\ Edmar Warlisson de Souza Alves*** \\ César Augusto de Castro Fiuza****
}

* Recebido em 24/11/2017

Aprovado em 16/12/2017

** Professor Universitário do Mestrado e da Graduação em Direito da Universidade de Itaúna (UIT), FACED (Divinópolis - MG), FADIPA (Ipatinga - MG) e da UNA (Belo Horizonte - MG); ex-bolsista CAPES e atual do FUNDEP/UFMG; Coordenador do Projeto Cidade Alteridade em Itaúna; Doutor em Direito Empresarial pela UFMG, Mestre e Especialista em Direito e Advogado. Avaliador de cursos do MEC. Email: eloy.junior@uol.com.br

*** Bacharel em Direito (Fundação Universidade de Itaúna, Minas Gerais). Advogado. Email: edmar_warlisson@hotmail.com

**** Doutor em Direito pela Universidade Federal de Minas Gerais. Professor da Faculdade Mineira de Direito e do Programa de PósGraduação Stricto Sensu em Direito da Pontifícia Universidade Católica de Minas Gerais. Professor da Faculdade de Direito da Universidade Federal de Minas Gerais. Professor do Programa de Pós-Graduação Stricto Sensu em Direito da Universidade FUMEC/MG. Professor colaborador na FADIPA. Advogado e consultor jurídico.Email: cesarfiuza@gmail.com

\section{Resumo}

O uso redes sociais e aplicativos de mensagens instantâneas tornou-se uma constante e veio facilitar a comunicação e troca de dados entre pessoas. No entanto, quando sua utilização envolve o ambiente de trabalho, é preciso ter cautela, pois o uso excessivo desses meios de comunicação pode gerar problemas para o empregado e empregador. Atualmente, não existe regulamentação que proíba o uso e acesso nas empresas e estas podem criar regras próprias. O presente artigo apresenta alternativas para os conflitos que possam surgir com base na análise dos direitos constitucionalmente assegurados ao cidadão. Após verificados esses elementos, concluímos que, até a elaboração de normas específicas, a melhor saída para evitar a ocorrência de conflitos envolvendo o uso dessas modernas ferramentas de comunicação social seria o estabelecimento de um código de ética pelo empregador, o que facilitaria a identificação da falta e da punição a ser aplicada. Antes de adentrar ao tema, esclarece-se que foi utilizado o método científico da pesquisa qualitativa e bibliográfica.

Palavras-chave: Direito do Trabalho. Relação de Trabalho. Redes Sociais. Demissão. Poderes Diretivos.

\section{Abstract}

The use of social networks and snapshots messages has become a constant and has facilitated communication and exchange of data between people. However, when using the work environment requires caution, as excessive use of application can create problems for the employee and employer. There are currently no regulations that prohibit the use in companies and they can create their own rules. The aim is to present alternatives to the conflicts that arise based on the analysis of the rights constitutionally assured to the citizen. After verifying these elements, we conclude that, until the elaboration of specific norms, the best way out to avoid the occurrence of conflicts involving the use of these modern social communication tools would be the establishment of a code of ethics by the employer, which 
would facilitate the identification of the fault and punishment to be applied. Before entering the subject, it is clarified that the scientific method of qualitative and bibliographic research was used.

Keywords: Labor law. Work relationship. Social Network. Resignation. Directive power.

\section{INTRODUÇÃo}

Este trabalho trata da análise do uso indevido das redes sociais e aplicativos de mensagens instantâneas na relação de trabalho e suas possíveis consequências. Hoje é comum haver nos Tribunais discussões que envolvam o uso, por exemplo, de Facebook, Twitter, LinkedIn, WhatsApp e Messenger no ambiente de trabalho, uma vez que, ainda, não há qualquer regulamentação legal sobre o tema.

Sendo assim, objetivou-se neste trabalho apresentar a história do Direito do Trabalho, sua evolução, a relação de trabalho subordinado e os direitos fundamentais do trabalhador, para que seja possível compreender o que vem ocorrendo e o que tem sido admitido pelos tribunais em relação ao uso dessas mídias sociais.

Inicialmente, será abordada a história do trabalho humano e do Direito do Trabalho no Brasil, apresentando a evolução das Constituições, como também, a evolução infraconstitucional.

Em seguida, buscou-se apontar o significado da subordinação e a importância dos poderes diretivos do empregador para a proteção de sua atividade.

No item quatro foram abordados os direitos fundamentais do trabalhador e, em particular, a dignidade da pessoa humana e o direito à privacidade e à liberdade no ambiente de trabalho.

A quinta divisão do artigo busca conceituar a tecnologia, apresentando os benefícios que esta trouxe às relações sociais e a sua associação à evolução humana.

Por fim, no sexto item, foram apresentadas algumas situações em que o uso das redes sociais e aplicativos de mensagens instantâneas mostra-se inconveniente e prejudicial às relações de trabalho, podendo trazer sério prejuízos.

O objetivo principal deste trabalho é apresentar a possibilidade de uso ou a vedação dos smartphones do ambiente de trabalho, à luz dos direitos e garantias previstos na Constituição Federal de 1988.

Este trabalho se valerá, essencialmente, do método bibliográfico, por meio da investigação científica por meio de doutrinas, legislações, jurisprudência e demais fontes escritas.

Busca-se apontar as divergências sobre o assunto, com o fim de possibilitar uma melhor reflexão sobre o tema, com base nos preceitos e garantias constitucionais, bem como à luz da evolução do próprio Direito.

\section{Conceito e história do trabalho humano e do direito do trabalho}

Para que se consiga analisar, numa visão ampla, os problemas atuais existentes nas relações de emprego, é imprescindível o conhecimento prévio do conceito de trabalho, como também, da evolução histórica do Direito do Trabalho, como será demonstrado adiante.

\subsection{Conceito de trabalho e de Direito do Trabalho}

O trabalho é uma figura constante em nossas vidas, entretanto, a tarefa de conceituar trabalho não é simples, uma vez que este está relacionado a diversos seguimentos.

$\mathrm{Na}$ história da humanidade, o trabalho confunde-se com a própria vida, uma vez que é o instrumento 
utilizado pelo homem para satisfazer suas necessidades mais básicas. Em outras palavras, pode-se afirmar que o homem interage juntamente aos recursos naturais disponíveis com o propósito de buscar os meios de assegurar sua existência.

Segundo Karl Marx, "o processo de trabalho, como o apresentamos em seus elementos simples e abstratos, é atividade orientada a um fim para produzir valores de uso, apropriação do natural para satisfazer a necessidades humanas [...]."

Sob o ponto de vista histórico e etimológico, a palavra trabalho deriva de algo desagradável: dor, castigo, sofrimento, tortura. A origem do termo vem do latim, "tripalium", que era uma espécie de instrumento de tortura ou canga que pesava sobre os animais. Desse modo, os nobres e os senhores feudais não trabalhavam, uma vez que consideravam o trabalho uma forma de castigo. ${ }^{2}$

Contudo, se no passado o trabalho era sinônimo de tortura, atualmente, tem a denotação de energia física ou intelectual empregada pelo homem com finalidade produtiva. Entretanto, nem toda atividade humana produtiva é objeto do Direito do Trabalho, tendo em vista que somente a realizada em prol de terceiros importa ao Direito Laboral. ${ }^{3}$

Em relação ao Direito do Trabalho, pode-se afirmar que se trata do ramo da ciência jurídica que estuda as relações jurídicas entre os trabalhadores e os tomadores de serviços, ou seja, entre os empregados e empregadores. ${ }^{4}$

A propósito:

[...] o Direito do Trabalho surgiu, no contexto histórico da sociedade contemporânea, a partir da Revolução Industrial, com vistas a reduzir, por meio da intervenção estatal, a desigualdade existente entre capital (empregador) e trabalho (empregado).

É exatamente daí que se extrai a principal característica do Direito do Trabalho: a proteção do trabalhador (e, notadamente, do trabalhador subordinado, que é o empregado $[\ldots .].)^{5}$

Embora seja alvo de muitas críticas, a maioria da doutrina pátria adota o entendimento de que o Direito do Trabalho é o conjunto de princípios e normas que regulam, de forma especial, as relações mediata ou imediatamente relacionadas ao trabalho remunerado livre, privado e subordinado, estando vinculado à existência dos que o executam. ${ }^{6}$

\subsection{História do Direito do Trabalho no Brasil}

As primeiras Constituições brasileiras estabeleciam apenas sobre a forma do Estado e o sistema de governo. Posteriormente, passaram a tratar de todos os ramos do Direito, inclusive do Direito do Trabalho, como ocorre, de forma semelhante, com a Constituição Federal de 1988.

A Constituição de 1824 tratou apenas de abolir as corporações de ofício, considerando que deveria haver liberdade do exercício de ofícios e profissões.

A Lei do Ventre Livre de 1871 dispôs que os filhos dos escravos nasceriam livres a partir de 28 de setembro daquele ano. Posteriormente, a Lei Saraiva-Cotegipe libertou os escravos com mais de 60 anos.

Em 1888 a famosa Lei Áurea foi assinada pela Princesa Isabel, que aboliu definitivamente a escravatura no Brasil.

1 MARX, K. O Capital: crítica da economia política. Tradução por Regis Barbosa e Flávio R. Kothe. São Paulo: Abril Cultural, 1985. Livro 1, v.1, t.1. (Os economistas).

2 CASSAR, Vólia Bomfim. Direito do trabalho. 11. ed. rev. e atual. Rio de Janeiro: Forense; São Paulo: Método, 2015.

CASSAR, Vólia Bomfim. Direito do trabalho. 11. ed. rev. e atual. Rio de Janeiro: Forense; São Paulo: Método, 2015.

RESENDE, Ricardo. Direito do trabalho esquematizado. 5. ed. rev. e atual. Rio de Janeiro: Forense; São Paulo: Método, 2015.

RESENDE, Ricardo. Direito do trabalho esquematizado. 5. ed. rev. e atual. Rio de Janeiro: Forense; São Paulo: Método, 2015 , p. 46.

6 CASSAR, Vólia Bomfim. Direito do trabalho. 11. ed. rev. e atual. Rio de Janeiro: Forense; São Paulo: Método, 2015. 
Em 1891, a Constituição reconheceu a liberdade de associação.

A Constituição de 1834 foi a primeira constituição brasileira a dispor, de forma específica, acerca do Direito do Trabalho. Por influência do constitucionalismo social, a Constituição de 1834 garantia a liberdade sindical, a isonomia salarial, o salário mínimo, jornada de oito horas de trabalho, proteção do trabalho das mulheres e menores, repouso semanal e férias anuais remuneradas. ${ }^{7}$

Marcando uma fase intervencionista do Estado, a Constituição de 1937, que decorreu do golpe de Getúlio Vargas, tinha conteúdo corporativista, e instituiu o sindicato único, imposto por lei e vinculado ao Estado.

Em 1943 foi sancionada a Consolidação das Leis do Trabalho - CLT, como uma forma de reunir as diversas leis esparsas que existiam sobre assuntos trabalhistas.

A Constituição de 1946 eliminou o corporativismo estabelecido por sua antecessora, estabelecendo diversos direitos trabalhistas, como participação dos trabalhadores nos lucros (art. 157, IV), repouso semanal remunerado (art. 157, VI), estabilidade (art. 157, XII), direito de greve (art. 158) e outros direitos que se encontravam na norma constitucional anterior. ${ }^{8}$

A Constituição de 1967 manteve os direitos trabalhistas da Constituição de 1946, porém, com algumas modificações.

Em 1988 foi promulgada a Constituição Federal, que apresentou um importante rol de garantias dos direitos básicos do trabalhador, fundamentados no princípio da dignidade da pessoa humana.

Segundo Ricardo Resende, em que pese a ampliação das garantias e dos direitos dos trabalhadores na Constituição de 1988, o capitalismo permanece exercendo pressão, podendo ocasionar uma desregulamentação trabalhista, sugerindo a aplicação do velho dogma liberal de que a relação de trabalho deveria ser regida por um simples contrato de prestação de serviços, na forma do direito comum.

\section{RELAÇÃo de EMPREgo}

Por meio do contrato firmado entre empregado e empregador, surge uma relação de emprego, todavia, para que essa relação reste caracterizada, é imprescindível a presença de cinco elementos: a prestação de serviço de uma pessoa física à outra pessoa física ou jurídica, que haja a pessoalidade, que a prestação de serviço não seja eventual e que ocorra mediante a subordinação do empregado ao empregador, e que seja uma relação onerosa.

Com o propósito de facilitar o estudo das hipóteses em que conflitam os direitos do empregado com os direitos do empregador pelo uso de redes sociais e aplicativos de mensagens instantâneas durante o horário de trabalho, será abordado neste capítulo a subordinação e os poderes diretivos do empregador, que são os principais pilares da relação de emprego.

\subsection{A subordinação e o dever de obediência do empregado}

A subordinação é o requisito principal para a caracterização da relação de emprego, constituindo o grande elemento diferenciador entre a relação de emprego e as demais relações de trabalho, apresentando inquestionável importância na fixação do vínculo jurídico empregatício.

7 MARTINS, Sérgio Pinto. Direito do Trabalho. 25. ed. São Paulo: Atlas, 2011.

8 MARTINS, Sérgio Pinto. Direito do Trabalho. 25. ed. São Paulo: Atlas, 2011. 
Na lição de Ricardo Resende:

Se, do ponto de vista histórico, a natureza da subordinação foi sempre controvertida, atualmente a doutrina e a jurisprudência adotam pacificamente a ideia de subordinação jurídica. Assim, a subordinação existente entre empregado e empregador é jurídica, tendo em vista que decorre do contrato estabelecido entre ambos (contrato de trabalho). ${ }^{9}$

Se, por um lado, o empregador exerce o poder de direção, podendo direcionar, objetivamente, a forma pela qual a energia de trabalho será disponibilizada, por outro lado, caberá ao empregado se submeter às ordens do empregador, fazendo surgir, desse modo, a subordinação jurídica. Segundo Ricardo Resende ${ }^{10}$, a contraposição à subordinação é a autonomia. Já quem é subordinado não trabalha por contra própria, não sendo senhor do destino de sua energia laboral.

Nesse sentido, esclarece Alice Monteiro de Barros:

Esse poder de comando do empregador não precisa ser exercido de forma constante, tampouco se torna necessária a vigilância técnica contínua dos trabalhos efetuados, mesmo porque, em relação aos trabalhadores intelectuais, ela é difícil de ocorrer. O importante é que haja a possibilidade de o empregador dar ordens, comandar, dirigir e fiscalizar a atividade do empregado. Em linhas gerais, o que interessa é a possibilidade que assiste ao empregador de intervir na atividade do empregado. Por isso, nem sempre a subordinação jurídica se manifesta pela submissão a horário ou pelo controle direto do cumprimento de ordens. ${ }^{11}$

Não obstante, Ricardo Resende ${ }^{12}$ alerta que é forçoso concluir que a submissão ao horário e ao controle direto do cumprimento de ordens não sejam imprescindíveis ao reconhecimento da subordinação, é relevante ressaltar que esses fatos não deixam de representar indícios fortes da existência da subordinação jurídica, que muitas vezes é fundamental para identificar a relação de emprego.

Maurício Godinho Delgado ${ }^{13}$ afirma que as dimensões objetiva e estrutural da subordinação teriam sido adotadas pelo legislador na nova redação do art. $6^{\circ}$ da CLT, embora, de forma implícita, nos seguintes termos:

Art. $6^{\circ}$ Não se distingue entre o trabalho realizado no estabelecimento do empregador, o executado no domicílio do empregado e o realizado a distância, desde que estejam caracterizados os pressupostos da relação de emprego. (Redação dada pela Lei n 12.551, de 2011)

Parágrafo único. Os meios telemáticos e informatizados de comando, controle e supervisão se equiparam, para fins de subordinação jurídica, aos meios pessoais e diretos de comando, controle e supervisão do trabalho alheio. (grifo nosso)

Portanto, esse dispositivo faz compreender que, além da clássica noção de subordinação, por meio de ordens diretas, há a possibilidade de reconhecimento da subordinação jurídica com base em meios telemáticos e informatizados de comando, como e-mail, comunicadores instantâneos (como Skype, WhatsApp etc.), entre outros, o que, de fato, revela o reconhecimento de outras dimensões de subordinação, além da clássica. ${ }^{14}$

\subsection{Poderes diretivos do empregador}

É cediço que o empregador conta com poderes de direção para controlar a tomação de serviços, podendo-se afirmar que todo trabalho subordinado é um trabalho dirigido. ${ }^{15}$

9 RESENDE, Ricardo. Direito do trabalho esquematizado. 5. ed. rev. e atual. Rio de Janeiro: Forense; São Paulo: Método, 2015 , p, 112.

10 RESENDE, Ricardo. Direito do trabalho esquematizado. 5. ed. rev. e atual. Rio de Janeiro: Forense; São Paulo: Método, 2015.

11 BARROS, Alice de Monteiro de. Curso de direito de trabalbo. 7. ed. São Paulo: LTr, 2011. p. 268.

12 RESENDE, Ricardo. Direito do trabalho esquematizado. 5. ed. rev. e atual. Rio de Janeiro: Forense; São Paulo: Método, 2015.

13 DELGADO, Maurício Godinho. Curso de direito do trabalho. 15. ed. São Paulo: Ltr, 2015.

14 RESENDE, Ricardo. Direito do trabalho esquematizado. 5. ed. rev. e atual. Rio de Janeiro: Forense; São Paulo: Método, 2015.

15 BASILE, César Reinaldo Offa. Direito do trabalho: duração do trabalho a direito de greve. 3. ed. São Paulo: Saraiva, 2011. 
Por meio do poder de direção, é possível ao empregador definir como serão desenvolvidas as atividades do empregado inerentes ao contrato de trabalho. $O$ fundamento legal do poder de direção é encontrado no art. $2^{\circ}$, caput, da CLT, que oferece a definição de empregador:

Art. $2^{\circ}$ - Considera-se empregador a empresa, individual ou coletiva, que, assumindo os riscos da atividade econômica, admite, assalaria e dirige a prestação pessoal de serviço. ${ }^{16}$

Na lição de Ricardo Resende:

O poder empregatício decorre do contrato de trabalho, consistindo no conjunto de prerrogativas conferidas ao empregador no sentido da direção da prestação dos serviços.

Portanto, o fundamento do poder empregatício é, para a doutrina amplamente majoritária, o próprio contrato de trabalho, consubstanciado em um acordo de vontades que origina a relação empregatícia e, a partir desta, faz surgir direitos e deveres para os contratantes (empregador e empregado). Neste complexo de direitos e obrigações encontra-se inserido o poder empregatício. ${ }^{17}$

Segundo a doutrina, o poder de direção compreende não apenas o poder de organizar suas atividades, mas também de controlar e disciplinar o trabalho, conforme os fins do empreendimento, podendo ser divido em três vertentes: poder de organização, poder de controle e poder disciplinar.

Além disso, por meio do poder de organização, o empregador definirá a estrutura jurídica a ser implantada para o melhor desenvolvimento de suas atividades, mediante empresa individual, sociedade por cotas de responsabilidade limitada, por ações etc. ${ }^{18}$

Igualmente, será por meio do poder de organização que o empregador determinará o número de funcionários que precisará, além da disposição de cargos, funções, local de trabalho etc., como também, poderá regulamentar o trabalho, elaborando o regulamento da empresa. ${ }^{19}$

O poder de controle determina que o empregador tem o direito de fiscalizar e controlar as atividades de seus empregados. Desse modo, há quem defenda a possibilidade da revista dos empregados, com fundamento no direito de propriedade do empregador, desde que esta prática observe os limites constitucionais e os direitos fundamentais dos trabalhadores.

Ademais, o poder de controle, também, dá direito ao empregador de verificar o cumprimento correto do horário de trabalho do obreiro etc., que tem, inclusive, amparo legal.

Ricardo Resende chama o poder de controle de "poder fiscalizatório", e assim o define:

É o poder de vigilância em relação ao ambiente interno da empresa e a prerrogativa que tem o empregador de fiscalizar o modo de prestação dos serviços.

São exemplos do poder fiscalizatório quaisquer formas de controle do ambiente de trabalho, como revistas pessoais, monitoramento por videocâmeras, monitoramento de e-mail, detector de metais, controle de horário, entre outros. ${ }^{20}$

O poder de controle e fiscalização não é absoluto, encontrando limites nos direitos fundamentais do cidadão, assegurados na Constituição Federal de 1988.

Em relação ao poder disciplinar, este é poder que o empregador tem de aplicar punições aos empregados em casos de descumprimento de suas obrigações contratuais. ${ }^{21}$

16 BRASIL. Consolidação das Leis do Trabalho. Decreto-lei n. 5.452 de $1^{\circ}$ de maio de 1943. Disponível em: < http://www.planalto. gov.br/ccivil_03/decreto-lei/Del5452.htm> Acesso em: 14 nov. 2017.

17 RESENDE, Ricardo. Direito do trabalho esquematizado. 5. ed. rev. e atual. Rio de Janeiro: Forense; São Paulo: Método, 2015. p. 344.

18 MARTINS, Sérgio Pinto. Direito do Trabalho. 25. ed. São Paulo: Atlas, 2011.

19 MARTINS, Sérgio Pinto. Direito do Trabalho. 25. ed. São Paulo: Atlas, 2011.

20 RESENDE, Ricardo. Direito do trabalho esquematizado. 5. ed. rev. e atual. Rio de Janeiro: Forense; São Paulo: Método, 2015. p. 345.

21 RESENDE, Ricardo. Direito do trabalho esquematizado. 5. ed. rev. e atual. Rio de Janeiro: Forense; São Paulo: Método, 2015. 
De fato, o poder disciplinar decorre do poder de obediência do empregado em relação às ordens efetuadas pelo empregador, considerando a subordinação jurídica estabelecida entre ambos por meio do contrato de trabalho.

Ricardo Resende ${ }^{22}$ afirma que "o problema do poder disciplinar é que seu exercício atinge, quase sempre, a personalidade do trabalhador".

Além disso, a maioria das condutas consideradas puníveis foram taxadas pela CLT, no art. 482:

Art. 482 - Constituem justa causa para rescisão do contrato de trabalho pelo empregador:

a) ato de improbidade;

b) incontinência de conduta ou mau procedimento;

c) negociação habitual por conta própria ou alheia sem permissão do empregador, e quando constituir ato de concorrência à empresa para a qual trabalha o empregado, ou for prejudicial ao serviço;

d) condenação criminal do empregado, passada em julgado, caso não tenha havido suspensão da execução da pena;

e) desídia no desempenho das respectivas funções;

f) embriaguez habitual ou em serviço;

g) violação de segredo da empresa;

h) ato de indisciplina ou de insubordinação;

i) abandono de emprego;

j) ato lesivo da honra ou da boa fama praticado no serviço contra qualquer pessoa, ou ofensas físicas, nas mesmas condições, salvo em caso de legítima defesa, própria ou de outrem;

k) ato lesivo da honra ou da boa fama ou ofensas físicas praticadas contra o empregador e superiores hierárquicos, salvo em caso de legítima defesa, própria ou de outrem;

1) prática constante de jogos de azar.

Parágrafo único - Constitui igualmente justa causa para dispensa de empregado a prática, devidamente comprovada em inquérito administrativo, de atos atentatórios à segurança nacional. (Incluído pelo Decreto-lei $n^{\circ} 3$, de 27.1.1966) ${ }^{23}$

Além das infrações típicas do art. 482, podemos verificar outros dispositivos isolados, como o parágrafo único do art. 158 da CLT, que determina que:

Art. $158-[\ldots]$

$[\cdots]$

Parágrafo único - Constitui ato faltoso do empregado a recusa injustificada: (Incluído pela Lei no 6.514 , de 22.12.1977)

a) à observância das instruções expedidas pelo empregador na forma do item II do artigo anterior; (Incluída pela Lei $n^{\circ}$ 6.514, de 22.12.1977)

b) ao uso dos equipamentos de proteção individual fornecidos pela empresa. (Incluída pela Lei n ${ }^{\circ} 6.514$, de 22.12.1977) ${ }^{24}$

Ressalte-se que ao empregado faltoso poderão ser aplicadas as seguintes penalidades: advertência (verbal

22 RESENDE, Ricardo. Direito do trabalho esquematizado. 5. ed. rev. e atual. Rio de Janeiro: Forense; São Paulo: Método, 2015. p. 349.

23 BRASIL. Consolidação das Leis do Trabalho. Decreto-lei n. 5.452 de $1^{\circ}$ de maio de 1943. Disponível em: <http://www.planalto. gov.br/ccivil_03/decreto-lei/Del5452.htm> Acesso em: 14 nov. 2017.

24 BRASIL. Consolidação das Leis do Trabalbo. Decreto-lei n. 5.452 de $1^{\circ}$ de maio de 1943. Disponível em: < http://www.planalto. gov.br/ccivil_03/decreto-lei/Del5452.htm> Acesso em: 14 nov. 2017. 
ou escrita); suspensão disciplinar (por até 30 dias); e demissão motivada (justa causa).

A advertência não tem previsão legal expressa, contudo, é aceita de forma unânime pela doutrina e pela jurisprudência, uma vez que configura punição menos gravosa ao empregado em relação às demais.

Já a suspensão disciplinar é uma pena intermediária, que, nos termos do art. 474 da CLT, não pode ser aplicada em prazo superior a 30 dias consecutivos, sob pena de caracterização da rescisão injusta do contrato de trabalho.

Por fim, a pena mais grave, que é a ruptura do contrato de trabalho por justa causa, além de extinguir o vínculo de trabalho, retira do empregado o direito às verbas rescisórias normalmente devidas em outras modalidades de rompimento contratual.

É ainda importante mencionar que não são admitidas punições como multa (com exceção do atleta profissional), que ofendam a dignidade, intimidade, a honra e o decoro do trabalhador; que consistem em ato discriminatório; e atos que, em outras circunstâncias, sejam lícitos, mas não podem ser aplicados como sanção, como é o caso da transferência. ${ }^{25}$

Além disso, é imprescindível que, no momento da aplicação da pena, o empregador observe diversos requisitos, como: a tipicidade da conduta; a gravidade; a autoria; o dolo ou a culpa; a adequação entra a falta e a pena aplicada; a proporcionalidade da pena aplicada; a imediaticidade ou imediatidade entre a conduta faltosa e a punição, sob pena de consideração de perdão tácito; a singularidade da pena (no bis in idem); a ausência de discriminação; e a gradação de penalidades, cuja observação é prudente, embora a lei não exija que as penas sejam aplicadas de forma gradativa. ${ }^{26}$

\section{Direitos fundamentais do trabalhador}

É cediço que o uso indevido das redes sociais no trabalho pode causar conflitos entre empregado e empregador. Entretanto, antes de abordar esses conflitos de forma específica, é fundamental discorrer acerca dos direitos fundamentais dos trabalhadores, que frequentemente são infringidos.

Ademais, parar melhor compreensão do uso indevido de redes sociais e aplicativos de mensagens instantâneas, é necessário conhecer, previamente, os direitos à liberdade e privacidade do trabalhador, uma vez que, nem sempre, o uso da internet ou redes sociais no trabalho é errôneo.

\subsection{Princípio da dignidade da pessoa humana no ambiente de trabalho}

A Constituição Federal de 1988 estabeleceu, no inciso III, do art. $1^{\circ}$ que a dignidade da pessoa humana é um direito fundamental:

Art. $1^{\circ}$ A República Federativa do Brasil, formada pela união indissolúvel dos Estados e Municípios e do Distrito Federal, constitui-se em Estado Democrático de Direito e tem como fundamentos:

$[\ldots]$

III - a dignidade da pessoa humana; $;^{27}$

Portanto, o direito à dignidade é inerente a todo o ser humano e deve ser respeitado em todos os âmbitos, inclusive, nas relações de emprego, uma vez que esse princípio foi estabelecido como forma de promoção

25 RESENDE, Ricardo. Direito do trabalho esquematizado. 5. ed. rev. e atual. Rio de Janeiro: Forense; São Paulo: Método, 2015.

26 RESENDE, Ricardo. Direito do trabalho esquematizado. 5. ed. rev. e atual. Rio de Janeiro: Forense; São Paulo: Método, 2015.

27 BRASIL. Constituição da República Federativa do Brasil de 1988. Disponível em: < http://www.planalto.gov.br/ccivil_03/constituicao/ConstituicaoCompilado.htm>. Acesso em: 20 maio 2016. 
dos direitos humanos e da justiça social.

Nas palavras de Luciana Cristina Souza,

Historicamente direitos fundamentais e dignidade da pessoa humana não nasceram e se desenvolveram como conceitos irmãos, mas aproximaram-se e se vincularam ao longo dos últimos anos de modo perceptível. Enquanto a dignidade humana teve uma origem de ética religiosa, os direitos fundamentais foram decorrência do pensamento moderno iluminista de garantia das liberdades. Mas, após o advento do Estado do Bem Estar Social e diante da necessidade de se assegurar efetividade material a esses direitos, tratados de modo meramente formal no positivismo, desenvolveu-se uma ligação jurídicopositiva entre eles, a qual passou a constar das Constituições, notadamente após a Segunda Guerra Mundial (1939-1945) em que regimes totalitários degradaram a dignidade da pessoa humana. ${ }^{28}$

Pode-se afirmar que o princípio da dignidade da pessoa humana é o mais universal de todos os princípios, e que este exerce regência sobre os demais, sendo o centro axiológico de todo o ordenamento jurídico.

A dignidade da pessoa humana é o núcleo de existência comum a todos os indivíduos, desse modo, impõe-se um dever geral de respeito e proteção a todos do gênero humano.

Amauri Mascaro do Nascimento ensina que:

A dignidade é um valor subjacente a numerosas regras de direito. A proibição de toda ofensa à dignidade da pessoa é questão de respeito ao ser humano, o que leva o direito positivo a protegê-la, a garanti-la e a vedar atos que podem de algum modo levar à sua violação, inclusive na esfera dos direitos sociais. ${ }^{29}$

Segundo Artur Francisco Mori Rodrigues Motta:

[...] a dignidade é essencialmente um atributo da pessoa humana pelo simples fato de alguém "ser humano", se tornando automaticamente merecedor de respeito e proteção, não importando sua origem, raça, sexo, idade, estado civil ou condição socioeconômica. ${ }^{30}$

Ricardo Resende ${ }^{31}$ afirma que o princípio da dignidade da pessoa humana traduz a noção de que o ser humano não é um fim em si mesmo, assim, não pode ser utilizado como meio parar atingir determinado objetivo. Portanto, está proibida a coisificação do homem, e, no caso do Direito do Trabalho, está vedada a coisificação do trabalhador, não podendo ser usado como mero objeto na busca incessante pelo lucro e pelos interesses do capital.

Se a dignidade da pessoa humana é um dos fundamentos da República brasileira, conforme já visto, esta deve ser vista como o respeito absoluto aos direitos fundamentais de todo ser humano, devendo-se assegurar a todos condições dignas de existência. ${ }^{32}$

É importante ressaltar que o dever de assegurar aos cidadãos condições de vida minimamente dignas cabe ao Estado, o que inclui o direito de ter um trabalho digno.

\subsection{Direito à privacidade e à liberdade no trabalho}

O art. $5^{\circ}$ da Constituição Federal de 1988 assim estabelece:

Art. $5^{\circ}$ Todos são iguais perante a lei, sem distinção de qualquer natureza, garantindo-se aos brasileiros e aos estrangeiros residentes no País a inviolabilidade do direito à vida, à liberdade, à igualdade, à segurança

28 SOUZA, Luciana Cristina. Dignidade humana na webesfera governamental brasileira. Revista Brasileira de Políticas Públicas, v. 7 , n. 3, 2017.

29 NASCIMENTO, Amauri Mascaro. Curso de direito do trabalbo: história e teoria geral do direito do trabalho: relações individuais e coletivas do trabalho. 26. ed. São Paulo: Saraiva, 2011. p. 462.

30 MOTTA, Artur Francisco Mori Rodrigues. A dignidade da pessoa humana e sua definição. Âmbito Jurídico, Rio Grande, XVI, n. 119, dez. 2013. Disponível em: < http://ambitojuridico.com.br/site/?n_link=revista_artigos_leitura\&artigo_id=14054\&revista_ caderno $=29>$. Acesso em: 20 maio 2016.

31 RESENDE, Ricardo. Direito do trabalho esquematizado. 5. ed. rev. e atual. Rio de Janeiro: Forense; São Paulo: Método, 2015.

32 PINHO, Rodrigo César Rebello. Teoria geral da constituição e direitos fundamentais. 11. ed. São Paulo: Saraiva, 2011. 
e à propriedade, nos termos seguintes:

$[\ldots]$

$\mathrm{X}$ - são invioláveis a intimidade, a vida privada, a honra e a imagem das pessoas, assegurado o direito a indenização pelo dano material ou moral decorrente de sua violação; ${ }^{33}$

Conforme se infere do comando judicial, todo ser humano tem direito à privacidade, que é o direito de não ter tudo o que diz respeito à sua vida exposto pela sociedade.

Segundo Nathália Masson:

Núcleo mais rescrito do direito à privacidade, a intimidade compreende as relações e opções mais íntimas e pessoais do indivíduo, compondo uma gama de escolhas que se pode manter ocultas de rodas as outras pessoas, até das mais próximas. Representa, pois, o direito de possuir uma vida secreta e inacessível a terceiros, evitando ingerências de qualquer tipo.

A vida íntima é, assim, aquela relacionada à identidade da pessoa humana, suas particularidades de foro moral, abrangendo sua sexualidade, sua autoestima, seus segredos e informações mais pessoais.

[...] a vida privada é mais abrangente e contém a intimidade, pois abarca as relações pessoais, familiares, negociais ou afetivas, do indivíduo, incluindo seus momentos de lazer, seus hábitos e seus dados pessoais, como os bancários e os fiscais. Nota-se que a tutela à vida privada não busca proteger segredos ou particularidades confidenciais de ninguém, tarefa que fica a cargo da tutela da intimidade. ${ }^{34}$

E, na lição dos ilustres doutrinadores Gilmar Mendes, Inocêncio Coelho e Paulo Branco afirmam:

O direito à privacidade é proclamado como resultado da sentida exigência de o indivíduo "encontrar na solidão aquela paz e aquele equilíbrio, continuamente comprometido pelo ritmo da vida moderna".

A reclusão periódica à vida privada é uma necessidade de todo homem, para a sua própria saúde mental. Além disso, sem privacidade, não há condições propícias para o desenvolvimento livre da personalidade. Estar submetido ao constante crivo da observação alheia dificulta o enfrentamento de novos desafios. A exposição diuturna dos nossos erros, dificuldades e fracassos à crítica e à curiosidade permanentes de terceiros, e ao ridículo público mesmo inibiria toda tentativa de autossuperação. Sem a tranquilidade emocional que se pode auferir da privacidade, não há muito menos como o indivíduo se autoavaliar, medir perspectivas e traçar metas. ${ }^{35}$

O direito à privacidade é imprescindível no ambiente laboral, principalmente em relação ao uso da internet, WhatsApp e outras redes sociais durante o horário de trabalho. Conforme será visto, a liberdade de comunicação e o direito ao respeito à vida privada do empregado muitas vezes pode ir de encontro com os interesses do empregador, principalmente se resultar em ineficiência dos serviços prestados, entretanto, a hipótese de tais conflitos deve ser analisada com cautela, conforme será melhor analisado adiante.

\section{Aspectos importantes acerca da tecnologia}

A expansão da internet por meio de conexões banda larga possibilitou às organizações a interligação de seus computadores, facilitando o acesso à informação e à comunicação.

De acordo com pesquisa realizada por Viana, Maia e Albuquerque,

O surgimento da rede mundial de computadores ocorreu nos Estados Unidos, nos anos 1950 e 1960, por meio da criação de um programa militar denominado de Advanced Research Projects Agency (ARPA).

33 BRASIL. Constituição da República Federativa do Brasil de 1988. Disponível em: < http://www.planalto.gov.br/ccivil_03/constituicao/ConstituicaoCompilado.htm>. Acesso em: 20 maio 2016.

34 MASSON, Nathália. Manual de Direito Constitucional. 3. ed. rev. ampl. e atual. Salvador: JusPodivm, 2015. p. $218-219$.

35 MENDES, Gilmar Ferreira; COELHO, Inocêncio Mártires; BRANCO, Paulo. Curso de Direito Constitucional. São Paulo: Saraiva, 2008. p. 378. 
A sua criação foi direcionada para as pesquisas e o mundo acadêmico e não ao mercado, como muitos podem imaginar. Nota-se, também, que a Internet é algo relativamente recente, mas, dada a velocidade de sua evolução, a impressão é de que já existe há muito mais tempo. ${ }^{36}$

Da mesma forma, o aprimoramento da internet possibilitou a evolução das tecnologias digitais, como o WhatsApp e outras redes sociais como o Facebook, Twitter etc., que muitas vezes são utilizados pelos usuários no ambiente organizacional.

Nas palavras de Colombo e Facchini Neto,

Nas redes sociais, como o Facebook, por exemplo, o internauta pode, em seu perfil, criar uma publicação (escrever o que está pensando), publicar uma foto ou vídeo, realizar uma transmissão ao vivo (live), compartilhar, bem como manifestar aprovação ou desaprovação através de emoticons, que são ícones que representam emoções.

Também é possível escrever nas publicações (posts) de outros usuários, bem como parabenizá-lo por seu aniversário ou por outras conquistas, e, inclusive, marcar pessoas, vinculando o que escreveu à timeline do usuário mencionado. ${ }^{37}$

Até pouco tempo atrás, os empregadores tinham o controle de tudo que o subordinado acessava em seus computadores, e, em muitos casos, determinava-se o bloqueio de alguns sites, por acreditar que seriam prejudiciais ao desenvolvimento do trabalho.

Não obstante, com a evolução das tecnologias e o surgimento da conexão sem fio (wifi/3G/4G), o acesso à internet e às redes sociais ultrapassaram as barreiras e limitações dos computadores das organizações, podendo ser realizados a qualquer tempo e local, por meio dos celulares (smartphones), notebooks, ipads e demais dispositivos móveis.

A facilidade de acesso tornou possível que o trabalhador escape dos bloqueios de acesso organizacional, ainda que o monitoramento interno continue presente.

O acesso de redes sociais por meio dos dispositivos móveis dificulta a intervenção e o monitoramento do ambiente do trabalho, fazendo com que o empregador perca parte do poder de organização e fiscalização.

Considerando-se a evolução digital que nos encontramos atualmente, pode-se afirmar que a utilização de tecnologias de informação e comunicação não é mais uma ferramenta meramente usual, mas uma rotina no dia a dia das pessoas. Desse modo, deve-se considerar a possibilidade de uma grande influência no ambiente de trabalho.

Verifica-se que, por um lado, a utilização das tecnologias de informação deixou de ser uma ferramenta usual no cotidiano das empresas, passando a ser essencial nas tarefas das organizações. Muitas empresas também a utilizam para a divulgação de seus produtos e serviços.

O avanço das tecnologias e a conectividade instantânea diante da internet alterou o fluxo da comunicação. Por meio de dispositivos móveis, o acesso às redes sociais como o WhatsApp, Facebook, entre outros, transcenderam a barreira da utilização esporádica e de entretenimento, tornando-se uma necessidade contínua, ou até mesmo, um vício. O número de usuários inscritos nas redes sociais no Brasil é surpreendente. Em 2010, 80\% dos internautas brasileiros integravam alguma rede social. ${ }^{38}$

Se, por um lado, as tecnologias facilitaram muito a comunicação e o desenvolvimento das atividades nos ambientes organizacionais, por outro lado, verifica-se que a possibilidade de acesso de redes sociais durante

36 VIANA, Janile Lima; MAIA, Cinthia Meneses; ALBUQUERQUE, Paulo Germano Barrozo de. O cyberbullying e os limites da liberdade de expressão. Revista Brasileira de Políticas Públicas, v. 7, n. 3, 2017.

37 COLOMBO, Cristiano; FACCHINI NETO, Eugênio. Ciberespaço e conteúdo ofensivo gerado por terceiros: a proteção dos direitos de personalidade e responsabilização civil dos provedores de aplicação, à luz da jurisprudência do Superior Tribunal de Justiça. Revista Brasileira de Políticas Públicas, v. 7, n. 3, 2017.

38 TELLES, André. A Revolução das Mídias Sociais. Casos, Conceitos, Dicas e Ferramentas. São Paulo: M.Books, 2010. 
o horário de trabalho de forma desenfreada e indevida pode trazer sérios prejuízos para a atividade, conforme será analisado no próximo capítulo.

\section{O USO DAS REDES SOCIAIS E APLICATIVOS DE MENSAGENS INSTANTÂNEAS NO AMBIENTE DE TRABALHO}

É cediço que aplicativos de mensagens instantâneas, assim como as demais redes sociais, facilitam a comunicação entre as pessoas, em qualquer hora e lugar. Entretanto, o uso dessas facilidades exige ética e bom senso, principalmente nas relações de trabalho.

Nos dias atuais é quase impossível encontrar uma pessoa que possua um smartphone e que não utilize para mensagens via WhatsApp ou visualização de Facebook e Instagram. O WhatsApp, por exemplo, surgiu oferecendo inúmeros benefícios, permitindo não apenas agilidade na troca de informações, mas também permitindo a comunicação de forma muito mais econômica.

Em que pese todos os benefícios trazidos pela facilidade na utilização de ferramentas de comunicação virtual, verifica-se que seu uso aumentou o número de ações trabalhistas na Justiça, cujo fato interessa ao Direito.

É imprescindível compreender que, no ambiente de trabalho, é necessário concentração, dedicação, produtividade e respeito, contudo, a internet e o uso de redes sociais e aplicativos de mensagens podem oferecer inúmeras distrações para aqueles que os utilizam.

O uso indevido de celulares ou da internet pode configurar desvio de conduta profissional, podendo gerar consequências graves ao empregado como demissão. Desse modo, a utilização das tecnologias de comunicação no ambiente laboral e seus possíveis impactos para as relações de trabalho serão analisadas neste capítulo.

\subsection{Uso indevido de redes sociais e aplicativos de mensagens instantâneas pelo empregado}

Conforme Chiavenato ${ }^{39}$, as pessoas não vivem isoladas, ou seja, possuem contato com outros indivíduos. Desse modo, elas relacionam-se de modo contínuo com outras pessoas ou com o ambiente a qual pertençam, por meio da comunicação.

Segundo Chamon $^{40}$, a comunicação é um fator importantíssimo à evolução humana, uma vez que permite que as ideais e aprendizados sejam difundidos ao longo de tempo.

Nesse sentido, se por um lado o uso dos aplicativos facilita a comunicação dos usuários, por outro, seu uso desenfreado pode gerar prejuízos para a atividade laboral.

Em razão de seu poder diretivo, o empregador pode exigir de seus empregados concentração total no trabalho, proibindo ou restringindo a utilização destes elementos para fins exclusivamente particulares e, caso essa imposição seja descumprida, poderá ocasionar sérios problemas ao empregado, tais como advertência, suspensão ou até mesmo ter seu contrato de trabalho rescindido por justa causa.

Não há dúvidas que a utilização de redes sociais e aplicativos para fins não profissionais acaba comprometendo o rendimento e a concentração no trabalho, sem contar que, pode, até mesmo, influenciar na imagem da empresa, na venda de seus produtos, ou seja, em sua credibilidade.

39 CHIAVENATO, I. Recursos humanos: o capital humano das organizações. 9. ed. Rio de Janeiro: Elsevier, 2009.

40 CHAMON, E. M. Q. O. Gestão integrada de organizações. Rio de Janeiro: Brasport, 2008. 
No âmbito do Direito do Trabalho, o uso de smartphones durante o horário de trabalho vem causando grande preocupação, uma vez que não retira apenas a concentração dos empregados, mas também pode colocar em risco informações sigilosas da empresa e seus clientes, em razão da facilidade de se repassar as informações pelo aplicativo.

Como já mencionado, há inúmeros benefícios na utilização do WhatsApp e demais redes sociais para o emprego, contudo, este deve ser um aliado ao trabalho, caso contrário, se for utilizado para uso exclusivamente pessoal, restará configurado os malefícios da tecnologia para a atividade laboral.

O que se verifica é a necessidade de haver ética entre o uso das mídias sociais e aplicativos e a atividade laboral, uma vez que "a internet é um instrumento de informação e entretenimento que absorve a atenção das pessoas por longos períodos." ${ }^{41}$

Destarte, não é ético deixar de cumprir as tarefas determinadas pelo empregador para ficar navegando na internet e conversando por mensagem para fins particulares.

No ordenamento jurídico brasileiro ainda não há leis específicas que regulamentam o uso do celular e da internet no trabalho, contudo, a jurisprudência tem entendido que no ambiente corporativo o tempo de trabalho deve se restringir a atividades relacionadas ao próprio trabalho. Assim, qualquer atividade pessoal poderá ser considerada como desvio de conduta.

Por fim, os empregadores têm autonomia para restringir o uso do celular e sobre a política de usos dos aparelhos no ambiente de trabalho, como forma de resguardar sua atividade.

\subsection{Uso das redes sociais e aplicativos de mensagens instantâneas para fins relacionados ao trabalho e o uso indevido pelo empregador}

Conforme já mencionado, a internet e as tecnologias de informação e comunicação radicalizaram o modo como as pessoas trabalham e se comunicam, favorecendo e ampliando o trabalho.

Inúmeras são as empresas que vendem e divulgam seus produtos pela internet, facilitando, assim, a expansão do negócio.

Com o surgimento das mídias sociais e aplicativos, verificou-se, outrossim, que essa ferramenta tem sido utilizada para facilitar a comunicação entre os próprios componentes da organização laboral, com fornecedores, colaboradores e até mesmo consumidores.

Contudo, quando se usa essa ferramenta para comunicação entre empregador e empregados, deve-se ter muita cautela para não incorrer em dois riscos: o de praticar algum ato desabonador à honra e imagem de alguém, provocando danos morais, e o de restar caracterizada a prática de horas extras pelo empregado por ser acionado pelo empregador por meio do WhatsApp fora do período que compreende a jornada de trabalho.

De fato, a resolução de problemas do trabalho pelo WhatsApp ou demais aplicativos no período de descanso poderá implicar o pagamento de horas extras pelo empregador, uma vez que o art. $6^{\circ}$ da CLT estabelece que não há distinção entre o trabalho realizado no estabelecimento do empregador ou o executado no domićlí:

Art. $6^{\circ}$ Não se distingue entre o trabalho realizado no estabelecimento do empregador, o executado no domicílio do empregado e o realizado a distância, desde que estejam caracterizados os pressupostos da relação de emprego. (Redação dada pela Lei no 12.551, de 2011)

A tecnologia existe para facilitar a comunicação, entretanto, não deve haver uma ligação ininterrupta

41 SOUZA, M. C. Ética no ambiente de trabalho: uma abordagem franca sobre a conduta ética dos colaboradores. Rio de Janeiro: Elsevier, 2009. p. 89. 
entre empregado e empregador. Se o empregado ficou prestando serviço por algum tempo ao empregador, pode haver hora extra, contudo, se ficou aguardando por contato, deve ser configurado o sobreaviso e imposto o pagamento de adicional de $1 / 3$ da hora normal.

A utilização do WhatsApp por meio dos famosos grupos no ambiente de trabalho deve ocorrer com muita cautela, uma vez que a exposição indevida de algum empregado, de forma que denigra sua imagem pode implicar, por meio de um conjunto de ações, em assédio moral e danos morais. O contrário, também pode se verificar, tendo em vista que algum comentário dos empregados poderá ofender a honra e a imagem do empregador.

\subsection{Punições pela utilização de redes sociais indevidamente durante o trabalho}

Conforme foi analisado no início deste trabalho, o empregador conta com poderes diretivos para poder conduzir da forma que entender melhor sua atividade.

Por meio desses poderes é possível que o empregador crie políticas e normas para uso de tecnologia no ambiente de trabalho, delimitando o uso de celulares, da internet, e das redes sociais por seus empregados.

Acerca da possibilidade desse controle, assim é a jurisprudência do Tribunal Regional do Trabalho da $12^{\mathrm{a}}$ região:

EMENTA: “RESTRIÇÃO AO USO DE TELEFONES CELULARES NO HORÁRIO DE LABOR. PODER DIRETIVO DO EMPREGADOR. A proibição do uso de aparelho celular pelo empregado, no período em que está laborando, está inserida no poder diretivo do empregador, porquanto tais equipamentos permitem que a qualquer momento o trabalhador interrompa suas atividades profissionais para dedicar-se a questões particulares, nem sempre de caráter urgente, desviando sua atenção. A interferência na concentração gera não apenas uma interrupção dos serviços, mas também pode provocar acidente de trabalho, pondo em risco a integridade física dos trabalhadores envolvidos na tarefa." (Ac. $3^{\text {a }}$ T. Proc. RO 0000852-84.2011.5.12.0032. Maioria, 20.03.12. Rel.: Juíza Maria de Lourdes Leiria. Disp. TRT-SC/DOE 30.03.12. Data de Publ. 02.04.12)

Nesse sentido, as câmeras de vídeo, a manutenção desses equipamentos para a proteção do patrimônio, fiscalização dos serviços e segurança dos próprios trabalhadores não implicam violação à intimidade dos empregados, mormente quando do conhecimento destes, exceto se instaladas em locais onde a privacidade dos trabalhadores deve ser resguardada, como refeitórios, vestiários e banheiros.

A proibição do uso de aparelho celular pelo empregado, no decorrer da jornada de trabalho, está amparada no poder diretivo do empregador, que deriva do direito constitucional à propriedade. Os celulares e outros dispositivos móveis permitem que a qualquer momento o empregado interrompa suas atividades profissionais para se dedicar a questões particulares, que muitas vezes não se tratam de assuntos urgentes, que poderiam justificar o ato.

É preciso se ter em conta que em determinadas atividades, o simples atendimento a uma chamada no telefone celular pode significar não apenas uma interrupção dos serviços, mas uma quebra na concentração que também pode por em risco à integridade física dos trabalhadores envolvidos na tarefa que está sendo executada.

Nesse contexto, a nosso ver não se afigura afronta à dignidade dos trabalhadores a retenção de seus telefones celulares, devidamente desligados, no período de labor. Essa medida somente representaria uma invasão de privacidade no caso de eventual violação aos registros pessoais gravados nos aparelhos, e assédio moral se tivesse propósito persecutório, voltada exclusivamente a determinado empregado.

Assim, nos casos de indisciplina e insubordinação à proibição de uso de aplicativos de mensagens instantâneas durante o período de trabalho, poderá até mesmo acarretar dispensa por justa causa. Segundo as alíneas b, e, g, h, j e k do art. 482 da CLT, 
Art. 482 - Constituem justa causa para rescisão do contrato de trabalho pelo empregador:

$[\cdots]$

b) incontinência de conduta ou mau procedimento;

$[\ldots]$

e) desídia no desempenho das respectivas funções;

$[\cdots]$

g) violação de segredo da empresa;

h) ato de indisciplina ou de insubordinação;

$[\cdots]$

j) ato lesivo da honra ou da boa fama praticado no serviço contra qualquer pessoa, ou ofensas físicas, nas mesmas condições, salvo em caso de legítima defesa, própria ou de outrem;

k) ato lesivo da honra ou da boa fama ou ofensas físicas praticadas contra o empregador e superiores hierárquicos, salvo em caso de legítima defesa, própria ou de outrem; ${ }^{42}$

Desse modo, infere-se da leitura do respectivo dispositivo legal que é possível, sim, a demissão por justa causa pelo uso inadequado de redes sociais e aplicativos de mensagens instantâneas no ambiente de trabalho, embora tal atitude requeira muita cautela.

Na hipótese de o empregador optar pela restrição do uso de celular e redes sociais no ambiente de trabalho, este deverá disponibilizar aos empregados uma linha fixa de telefonia para uma eventual necessidade de comunicação fora do ambiente de trabalho, até porque deixar os empregados totalmente incomunicáveis poderia resultar em uma afronta à dignidade da pessoa humana.

Seguindo o princípio da graduação, é recomendável que, se as orientações do empregador quanto ao uso do celular e aplicativos não sejam seguidas, o empregado pode ser advertido, suspenso, e conforme o caso pode até mesmo ser demitido, no caso de não cumprir a conduta expressa determinada pelo empregador ou na hipótese de divulgar, por meio do WhatsApp, informações sigilosas e comprometedoras que violem o segredo da empresa.

\section{Considerações finais}

O trabalho é inerente ao ser humano e sempre o acompanhou, desde o surgimento das primeiras civilizações, sendo o hoje o pilar que sustenta a sociedade.

Com o desenvolvimento das relações comerciais e o surgimento de novas necessidades do ser humano, houve a evolução da tecnologia, que provocou mudanças bruscas no modo de produção, de trabalho e até mesmo no comportamento das pessoas.

A evolução tecnológica está atualmente em todo lugar. Pode-se afirmar que a internet revolucionou a forma como as pessoas trabalham, permitindo a otimização do modo de trabalhar e das ferramentas de trabalho.

A internet trouxe, sem dúvidas, muitos pontos positivos para o trabalho, todavia, tanta tecnologia terminou por aproximar o lazer e o trabalho, por meio da mobilidade dos smartphones. Assim, basta ligar o celular para que seja possível estar conectado com a internet, Facebook, WhatsApp, Messenger e demais

42 BRASIL. Consolidação das Leis do Trabalho. Decreto-lei n. 5.452 de $1^{\circ}$ de maio de 1943. Disponível em: < http://www.planalto. gov.br/ccivil_03/decreto-lei/Del5452.htm> Acesso em: 14 nov. 2017. 
redes sociais, tendo acesso ao que mais gosta de ver e ouvir.

O que seria, em tese, apenas benefícios, terminou por trazer problemas para o ambiente laboral, como a redução da produtividade gerada pelo uso inadequado do telefone celular e seus aplicativos.

Verifica-se que, nas relações de trabalho, é constante a falta de percepção do que é profissional do que é pessoal.

Ocorre que não são apenas os empregados que usam irregularmente as redes sociais e aplicativos de mensagens instantâneas, mas também os empregadores, que muitas vezes utilizam essa ferramenta tecnológica para manter o empregado conectado e trabalhando fora da jornada de trabalho, ou então, a usam indevidamente para expor seus empregados ou para corrigi-los, de forma degradante.

Essas situações formam um desafio aos juristas atuais que terão que enfrentá-las, embora não exista lei que regulamente essas práticas específicas.

Contudo, é possível, do ponto de vista constitucional, que o empregador vede a utilização das redes sociais no ambiente de trabalho por meio de regulamentação própria, em virtude de seus poderes diretivos. Todavia, eventual proibição não pode tornar os trabalhadores integralmente incomunicáveis, sob pena de afronta aos direitos fundamentais e à dignidade da pessoa humana.

Vislumbra-se, por meio deste trabalho, que até a elaboração de normas específicas, a melhor saída para evitar a ocorrência de conflitos envolvendo o uso dessas modernas ferramentas de comunicação social seria o estabelecimento de um código de ética pelo empregador, o que facilitaria a identificação da falta e da punição a ser aplicada, haja vista que é indubitável que o uso de redes sociais e de aplicativos de mensagem instantânea para fins particulares não urgentes causam prejuízos graves à atividade do empregador.

\section{REFERÊNCIAS}

ALMEIDA, Gregório Assagra de. Direito Processual do Trabalho. 6. ed. São Paulo: LTR, 2016.

BARROS, Alice de Monteiro de. Curso de direito de trabalho. 7. ed. São Paulo: LTr, 2011.

BASILE, César Reinaldo Offa. Direito do trabalho: duração do trabalho a direito de greve. 3. ed. São Paulo: Saraiva, 2011.

BRASIL. Consolidação das Leis do Trabalho. Decreto-lei n. 5.452 de $1^{\circ}$ de maio de 1943. Disponível em: <http://www.planalto.gov.br/ccivil_03/decreto-lei/Del5452.htm>. Acesso em: 14 nov. 2017.

BRASIL. Constituição da República dos Estados Unidos do Brasil. Disponível em: < http://www.planalto.gov.br/ ccivil_03/Constituicao/Constituicao34.htm>. Acesso em: 20 maio 2016.

BRASIL. Constituição da República dos Estados Unidos do Brasil. Disponível em: <http:/ /www.planalto.gov.br/ ccivil_03/Constituicao/Constituicao37.htm>. Acesso em: 20 maio 2016.

CALVO, Adriana. A busca da efetividade do direito fundamental à proteção do trabalhador no ambiente penoso: reflexões pós-positivas sobre o adicional de penosidade. In: ALMEIDA, Renato Rua de; CALVO, Adriana (Org.). A aplicação da teoria do diálogo das fontes no direito do trabalho. São Paulo: LTR, 2015.

CASSAR, Vólia Bomfim. Direito do trabalho. 11. ed. rev. e atual. Rio de Janeiro: Forense; São Paulo: Método, 2015.

CHAMON, E. M. Q. O. Gestão integrada de organizações. Rio de Janeiro: Brasport, 2008.

CHIAVENATO, I. Recursos humanos: o capital humano das organizações. 9. ed. Rio de Janeiro: Elsevier, 2009.

COLOMBO, Cristiano; FACCHINI NETO, Eugênio. Ciberespaço e conteúdo ofensivo gerado por tercei- 
ros: a proteção dos direitos de personalidade e responsabilização civil dos provedores de aplicação, à luz da jurisprudência do Superior Tribunal de Justiça. Revista Brasileira de Políticas Públicas, v. 7, n. 3, 2017.

DELGADO, Gabriel Neves. Direito fundamental ao trabalho digno. 2. ed. São Paulo: LTR, 2015.

DELGADO, Maurício Godinho. Curso de direito do trabalho. 15. ed. São Paulo: Ltr, 2015.

GRINOVER, Ada Pellegrini. O controle jurisdicional de políticas públicas. Rio de Janeiro: Forense, 2013.

LEMOS JUNIOR, Eloy Pereira. Empresa \& Função Social. Curitiba: Juruá, 2008.

MARTINS, Sérgio Pinto. Direito do Trabalho. 25. ed. São Paulo: Atlas, 2011.

MARX, K. O Capital: crítica da economia política. Tradução por Regis Barbosa e Flávio R. Kothe. São Paulo: Abril Cultural, 1985. Livro 1, v.1, t.1. (Os economistas).

MASSON, Nathália. Manual de Direito Constitucional. 3. ed. rev. ampl. e atual. Salvador: JusPodivm, 2015.

MENDES, Gilmar Ferreira; COELHO, Inocêncio Mártires; BRANCO, Paulo. Curso de Direito Constitucional. São Paulo: Saraiva, 2008.

MORAIS, José Luis Bolzan de; BRUM, Guilherme Valle. Políticas públicas e jurisdição constitucional: entre direitos, deveres e desejos. Porto Alegre: Livraria do Advogado, 2016.

MOTTA, Artur Francisco Mori Rodrigues. A dignidade da pessoa humana e sua definição. Ámbito Jurídico, Rio Grande, XVI, n. 119, dez. 2013. Disponível em: <http://ambitojuridico.com.br/site/?n_link=revista_ artigos_leitura\&artigo_id=14054\&revista_caderno=29>. Acesso em 20 maio 2016.

NASCIMENTO, Amauri Mascaro. Curso de direito do trabalho: história e teoria geral do direito do trabalho: relações individuais e coletivas do trabalho. 26. ed. São Paulo: Saraiva, 2011.

PINHO, Rodrigo César Rebello. Teoria geral da constituição e direitos fundamentais. 11. ed. São Paulo: Saraiva, 2011.

RESENDE, Ricardo. Direito do trabalho esquematizado. 5. ed. rev. e atual. Rio de Janeiro: Forense; São Paulo: Método, 2015.

ROSANVALLON, Pierre. El buen gobierno. Trad. Horacio Pons. Buenos Aires: Manantial, 2015.

SOUTO MAIOR, Jorge Luiz. O conflito entre o novo CPC e o processo do trabalho. 2015. Disponível em: <www. anamatra.org.br>. Acesso em: 05 ago. 2016.

SOUZA, Luciana Cristina. Dignidade humana na webesfera governamental brasileira. Revista Brasileira de Políticas Públicas, v. 7, n. 3, 2017.

SOUZA, M. C. Ética no ambiente de trabalho: uma abordagem franca sobre a conduta ética dos colaboradores. Rio de Janeiro: Elsevier, 2009.

TELLES, André. A Revolução das Mídias Sociais. Casos, Conceitos, Dicas e Ferramentas. São Paulo: M. Books, 2010.

VIANA, Janile Lima; MAIA, Cinthia Meneses; ALBUQUERQUE, Paulo Germano Barrozo de. O cyberbullying e os limites da liberdade de expressão. Revista Brasileira de Políticas Públicas, v. 7, n. 3, 2017. 
Para publicar na revista Brasileira de Políticas Públicas, acesse o endereço eletrônico www.rbpp.uniceub.br

Observe as normas de publicação, para facilitar e agilizar o trabalho de edição. 